\title{
e-Governance in Davao Region: An Assessment of City Government Websites
}

\author{
Glenne Berja Lagura, MPA \\ Institute of Management, Governance and Continuing Studies \\ Davao del Norte State College \\ 8105 New Visayas, Panabo City, Davao del Norte, Philippines \\ ORCID No. 0000-0003-4142-2771
}

Received: July 10, 2017 Accepted: July 27, 2017 Online published: August 25, 2017

doi:10.5296/jpag.v7i3.11515 URL: https://doi.org/10.5296/jpag.v7i3.11515

\begin{abstract}
The study evaluated the resources and services available in the official government websites of all the cities in Davao Region to determine the extent of its implementation of e-governance. In particular, the assessment was done to verify if the following contents were promoted in their websites: (a) citizen awareness and understanding of their community's characteristics; (b) efficiency and effectiveness in service delivery; (c) transparency and accountability in operations and services; (d) awareness of policy making process and participation in decision making; (e) linkage and interaction between government and citizens and other groups; and (f) linkage between government and business. Moreover, the compliance of the city websites in posting the reports required by the Full Disclosure Policy (FDP) was also determined.

Results were initially obtained through an assessment done by the researcher using the checklist adapted from the study of Siar (2007). Preliminary findings were triangulated and substantiated from the Focus Group Discussion (FDG) with thirty (30) information technology participants who scrutinized the available contents in each of the website using the same checklist. Frequency counts, means and percentages were utilized from the derived significant discussions.

Findings showed that relatively low results were acquired by the city websites in Davao Region except for Davao and Tagum where most of the contents were promoted in the site. Moreover, the websites of both cities have advanced features and services which were not included in the checklist. As to the FDP compliance, findings revealed that except for Digos, all cities utilized their website to post the reports required under the FDP.
\end{abstract}


The study concludes that while all cities have utilized their websites for e-governance, the quality of its contents show substandard adoption and underutilization. The study suggests that each city exploit the benefits offered by the websites as a medium in promoting innovative public service delivery.

Keywords: Citizen Participation, e-Governance, Transparency, Government Websites, Good Governance, Full Disclosure Policy

\section{Introduction}

The constant tremendous development in the field of Information and Communication Technologies (ICTs) in this modern era continues to influence the manner of how government should look into improving efficient and effective public service and promotion of transparency in order to boost responsiveness; this is the so-called e-government. In fact, the once unreachable government's vital information such as budgets and spending are now made accessible to the general public through website as a medium.

At present, the rampant utilization of government websites to publish tremendous amount of information is observable. As a matter of fact, most countries are going beyond basic websites through providing national portals for the citizens to be connected to government services (UN e-Government Survey, 2010). Even the local governments around the world have their own website and regularly enhance its contents in order to develop better engagement with the citizens. This follows Darlington and Pitts (2012) who said that local government websites have to shift from a simple and ease of use website management to a more engaging, personalized and sophisticated one such as providing a relevant roadblock, or a message that appears over the web page which has to be dismissed or followed.

In the Philippines, several provincial, city, municipal and some barangay (village) local government units (LGUs) have their own website. A study which analyzes the 102 websites of all the City Governments in the country accessed in 2004 was conducted by Siar (2007). This study aims to fill in and update some previous related studies through comprehensively investigating the content and information contained in each city government website in order to determine the scope, usefulness, degree of transparency and effectiveness in improving the governance process.

It has been 10 years since the study was published by Siar (2007) and almost a decade has passed since the websites that were included in the study were accessed last 2004. Various developments in information and communication technology (ICT), in particular to the transformation of e-governance in the country, has been noticeable. The very recent is the implementation of the Full Disclosure Policy (FDP) which was started last 2010 as spearheaded by the late DILG Secretary, Jesse Robredo.

Through FDP, Local Government Units (LGUs) have been encouraged to practice the culture of transparency and accountability in public service by means of fully disclosing to the general public the required reports and documents through posting in at least three conspicuous places including the official government website of the local government unit. 


\section{Macrothink}

Journal of Public Administration and Governance ISSN 2161-7104 2017, Vol. 7, No. 3

Thus, there is a need to update the current status of e-governance focusing on assessing the contents of the government websites of all the cities in Davao Region. In addition, the implementation of the FDP policy particularly the prerequisite of posting the required reports and documents at the government websites makes it imperative to know the extent of compliance of the concerned city LGUs to this requirement. Hence, this study.

\section{Framework}

Theory Base. The study is anchored on the e-Government framework formulated by Nour, AbdelRahman and Fadlalla (2008). The said framework is divided into four dimensions namely access, availability, equity and democracy (see Figure 1).

In the said framework, the future of e-Governance is discussed in each of the four dimensions. Access is meant as the provision of information in related to governance scheme which is made to be available to the general public. The manner of increasing the efficiency, effectiveness and the quality of the system is what availability tells; it involves also the promotion of awareness and understandability among persons involved. Equity is enhancing the responsiveness, accountability, transparency, effectiveness and quality of life and democracy as the promotion of integrity, accountability and transparency.

\begin{tabular}{|c|c|}
\hline Democracy & Equity \\
\hline Access & Availability \\
\hline
\end{tabular}

Source: Nour, et al., 2008

Figure 1. Four-Dimensional e-Government Framework

Conceptual Framework. The conceptual framework formulated determines the condition of e-Governance implementation in all the cities of Davao Region. Six government websites were assessed focusing on the contents of information and reports available.

The study utilized the framework used by Siar (2007) in assessing the quantity of websites. Moreover, the formulation of the framework is inspired in the Four-Dimensional e-Government Framework by Nour, et al. (2008) which emphasized about the need to have an accessible and transparent e-Governance system.

There are two (2) main variables available; the independent variable which comprises the two indicators namely, contents of information and posting of the FDP required reports and the dependent variable which are the concerned city websites in Davao Region (see Figure 2). 


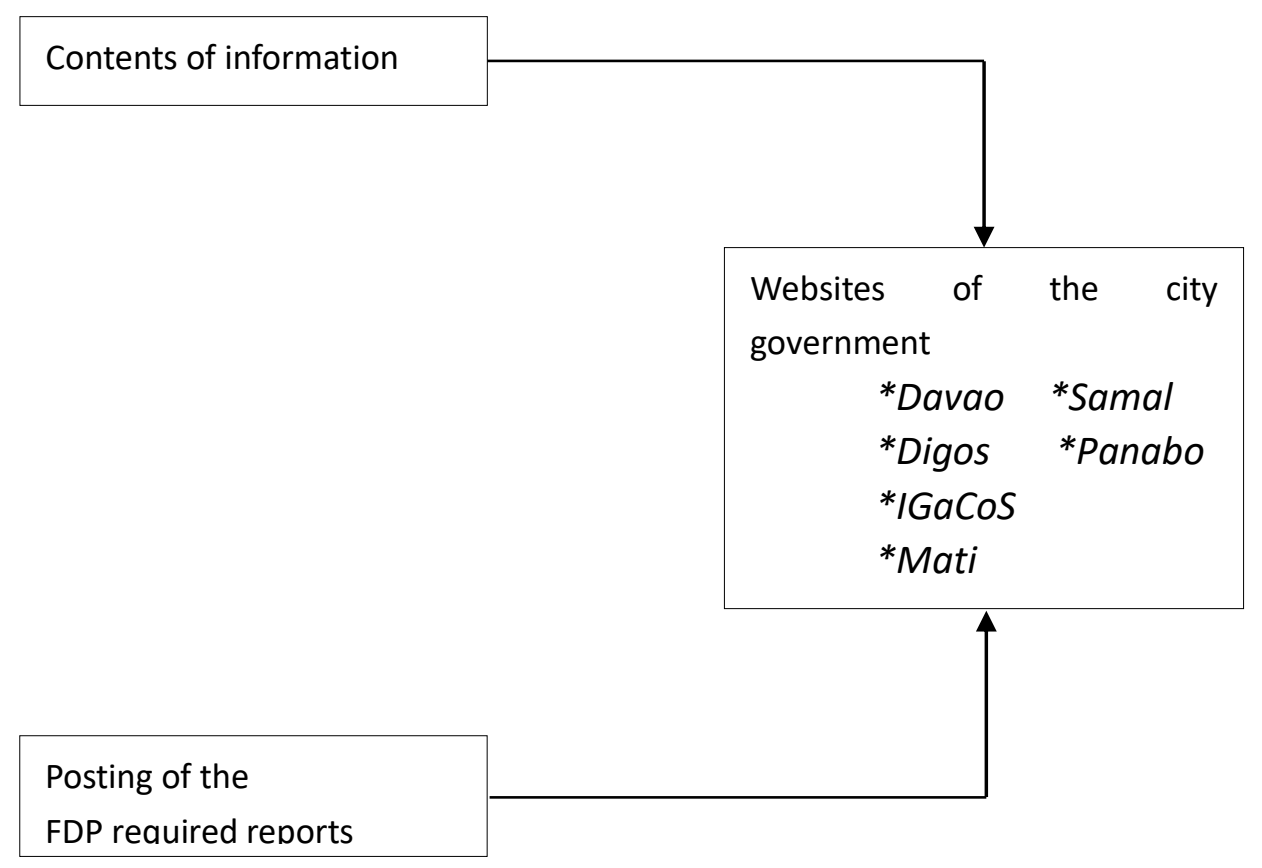

Figure 2. Conceptual Framework Showing the Variables of the Study

\section{Objectives}

The primary aim of the study is to provide a perspective as to what extent the local government of the cities in Davao Region implemented e-governance. In specific terms, the study looked into the content of the websites and examined the services and resources of each city. Moreover, the research determined the compliance of the city government in implementing FDP in the manner of posting the required documents at their official government website. Lastly, the study tried to come up with an analysis as to the current status of the concerned cities in implementing e-governance along with a comparison of the contents of information and the posting of the contents of information and the posting of the FDP required reports. The translated assessment that was examined aimed to provide feedback that will be useful in the improvement of e-governance in the cities of Davao Region.

\section{Methodology}

Method Used. The study was predominantly concerned in attaining the answers in the questions "what is the update?" and "do they comply?" thus this is an evaluative type of research. According to Weiss (1998), evaluation is the systematic assessment of the operation and/or the outcomes of a program or policy, compared to a set of explicit or implicit standards, as a means of contributing to the improvement of the program or policy.

Simultaneously, the study employed qualitative research method to allow the views, opinions, comments and observations of the researcher and the respondents to be included in the assessment. 
Sources of Data. This research used both primary and secondary data. Primary data involved the quantified results drawn from the evaluation conducted through the checklist used by the researcher in evaluating the contents of the concerned websites and also from the garnered data through the questionnaire made as evaluated by the respondents to triangulate the initial data gathered by the researcher who also acted as an evaluator. Secondary data comprised the official documents posted at the City Government websites which were retrieved by the researcher.

Moreover, during evaluation of the websites and the conducted focus group discussion, a personal comment was taken account of by the researcher and evaluators as per observations during the assessment in order to come up with qualitative information. Though the outputs of these exercises are considered to be a subjective finding, still these were viewed to be a vital deliberation in giving enrichment for the overall outcome of the study.

Data Gathering Instrument. While the study mainly relied on the data obtained in the evaluation of the websites in order to guarantee reliable results, such adaptation of data gathering instrument was made from the output formulated in the study of Siar (2007).

The checklist scheme "Functional Categorization in the Assessment of Web Content" by Siar (2007) was used in finding out the answer as to the web contents of the cities' websites (see Appendix B). The items per function in the instrument queried the websites' services and resources that can be obtained. The researcher per se serves as the initial evaluator and later provided a questionnaire as utilized by the selected respondents who participated in focus group discussions. The content of the questionnaire used by the respondents was the same as the contents of the instruments used by the researcher (see Appendix C) but the manner of evaluating the contents was based according to the below scoring guides in Table 1.

Lastly, in order to know the availability of the reports required by FDP, the researcher prepared a dummy table that was filled-out once certain reports were retrievable or not at the portal.

Table 1. Scale of Option Used in the Assessment of Website

\begin{tabular}{|c|c|c|l|}
\hline $\begin{array}{c}\text { Numerical } \\
\text { Rating }\end{array}$ & $\begin{array}{c}\text { Range } \\
\text { Interval }\end{array}$ & Description & \multicolumn{1}{|c|}{ Remarks } \\
\hline 5 & $4.50-5.0$ & Excellent & $\begin{array}{l}\text { When the expected outcome of the indicator } \\
\text { during assessment meets the respondent's } \\
\text { expectations 85\% to 100\% of the time. }\end{array}$ \\
\hline 4 & $3.50-4.49$ & Good & $\begin{array}{l}\text { When the expected outcome of the indicator } \\
\text { during assessment meets the respondent's } \\
\text { expectations 70\% to 84\% of the time. }\end{array}$ \\
\hline 3 & $2.50-3.49$ & Average & $\begin{array}{l}\text { When the expected outcome of the indicator } \\
\text { during assessment meets the respondent's } \\
\text { expectations 55\% to 69\% of the time. }\end{array}$ \\
\hline 1 & $1.50-2.49$ & Poor & $\begin{array}{l}\text { When the expected outcome of the indicator } \\
\text { during assessment meets the respondent's } \\
\text { expectations 40\% to 54\% of the time. }\end{array}$ \\
\hline & $1.0-1.49$ & Unsatisfactory & $\begin{array}{l}\text { When the expected outcome of the indicator } \\
\text { during assessment meets the respondent's } \\
\text { expectation less than 40\% of the time. }\end{array}$ \\
\hline
\end{tabular}


Sampling Technique. To triangulate the data obtained by the researcher during the initial evaluation using the checklist scheme, a focus group discussion (FGD) was further conducted. Clustered sampling was used in selecting 30 respondents belonging in the field of information technology (IT). Moreover, purposive sampling were utilized in picking 10 third year IT students, 10 first year IT students and 10 IT instructors to participate in the three sessions set for FGD.

Procedure of the Study. Painstaking researches were done first by the researcher via Internet in looking for any relevant references that could aid in conducting the chosen study. Varied related literatures and studies were found and noted which served as a help for the conceptualization of the problem queried. Prior to the scheduled outline defense last February 12, 2013, several consultations and meetings with the thesis adviser were held for the checking of the proposed research study. As provided in the minutes during the outline defense, the researcher then work out for the comments and suggestions of the approved study along with the defined scope and nature of conducting it.

The researcher individually accessed each of the government city websites in Davao Region. In obtaining the information as to the current profile of the government websites of the cities in Davao Region, their websites were visited and evaluated as to its contents. In knowing the availability of the website contents of the concerned LGU, an instrument adapted from the study of Siar (2007) was utilized in identifying and examining the contents available.

The initial assessments was made initially by the researcher; in the conduct of evaluation some screenshots were captured in the websites and insightful comments and observations are carefully noted for the purpose of valuable deliberation in discussing the results and in giving recommendations in the latter part of the study. After accomplishing the checklist scheme, the researcher submitted a letter to the Dean of the institute where the researcher conducted the focus group discussion. The contents of the letter contained the name of the respondents, together with the schedule and the room to be utilized in the conduct of the forum.

As the Dean allowed the conduct of the discussion to be made, the researcher then immediately held the forum. Three sessions were held and each session was participated by a total of 30 respondents to name, 10 third year IT students, 10 are first year IT students and 10 IT instructors in separate session where every session last for about three hours. The accomplished instrument filled in by the respondent during the forum was the same checklist used by the researcher during the initial assessment, but the respondent were required not just to check the availability of the items inquired but also to rate the presence of each of the item in every city LGU website.

During the conduct of each FDP, each of the respondents was provided with a computer unit connected to the internet for them to individually explore the subject websites along with the list of the URL of all the official government websites to be evaluated. Equipped with the LCD projector, the researcher then utilized the first one hour in discussing the purpose of the discussion, clarifying some unclear items inquired and familiarization on the section of the websites where specific items can be located in order to fasten the concurrent evaluation of 
all the 81 items queried. The remaining two hours were utilized for assessing the presence of every item in the websites of the concerned LGUs, for entertaining deliberative discussions and queries as well as for letting the respondent write their individual comments in the blank space provided in the instrument (see Appendix D).

Subsequent to the above procedures, the researcher then tabulated the data obtained in the questionnaires responded. Moreover, in order to assess the manner of pursuance of the city LGU to the FDP in the manner of posting the reports in the websites, the researcher used the table drawn in checking the availability of the reports inquired from 2010 to 2012. Lastly, to know how the city LGUs posted the reports in their websites, the researcher then captured some screenshots to identify and compare their ways in posting the reports.

Statistical Treatment. The following descriptive statistic tools were utilized in this study:

Frequency. To determine how frequent the items in the checklist are promoted in the city websites in Davao Region; how many items were available in each of the city per function as accorded in the adapted function scheme; and how many relevant FDP reports are posted in each of the website.

Mean. To know what is the average of the contents promoted by the city per function; what is the average of each of the city websites as rated by the participants in promoting the items; and what is the average rating of the websites of Davao Region in promoting the contents per function as rated by the participants.

Percentage. To find out how many percent of the items listed were promoted in the city websites of Davao Region per city and per function; and how many percent of the individual FDP reports were posted in the city websites of Davao Region in three years' time.

\section{Results and Discussion}

Status of the Cities' Websites. The prevalent typical information contained in most of the websites in Davao Region was apparently about the connection between city government and business sectors (Function 6) where 58\% were garnered by the cities' websites. It was followed by Function 1 for having 56\% garnered average of the information which promotes awareness of the citizens in understanding the characteristics of their community.

However, only $43 \%$ of all the items queried in Function 3 serve as the average contents of the websites concerned. Though there were two city websites, Davao and Tagum which got all the items that promote transparency and accountability, other websites got a low outcome.

While Davao and Tagum websites were sufficient enough in posting contacts of the officials and offices as well as making available of either vertical or horizontal communications, some other websites poorly provided these contents. An average of $40 \%$ is the total outcome of the websites in Function 5. To continue, an average of 33\% were garnered for Function 2 out of all the contents of the websites since almost all of the websites does not have downloadable forms in securing relevant permits and not of all websites displayed contents concerning to procedures in applying and/or availing pertinent documents. 
Extremely low result can be found in Function 4 where $25 \%$ is the percentage of the websites in the contents queried in this specific function. Four of the city websites did not have any item inquired relating to the awareness of policy making and participation in decision making while Davao and Tagum got only 1 and 2 items respectively.

The functions wherein average contents were less than 50\% are Function 2, 3, 4 and 5 where contents respectively inquired about delivery of frontline services, transparency and accountability, public awareness in policy making and their participation in decision making and linkage between city government, citizens and other groups.

Compliance to Full Disclosure Policy. Among the 13 reports required, the most complied documents as posted in the concerned websites were the budget reports, specifically the annual posting of Budget and Statement of Receipts and Expenditures wherein 56\% of the 18 items queried in both items were displayed on the sites. For the Statement of Debt Services report, $44 \%$ were obtainable, the same percentage for the Statement of Cash Flow report which is required on a quarterly basis.

For the procurement reports, the highest garnered percentage was 39\% for the posting of the Annual Procurement Plan or List. While both Trust Fund and SEF Utilization reports were the most complied report in the special fund reports category having both a percentage of $39 \%$.

It was individually presented that every year each city is required to post 34 reports, so for the 6 cities a total of 204 reports were inquired yearly. As observed in the table there was a gradual rate of compliance of the city websites, where in the year 2010, a total of 41 reports out of 204 can be obtained among the websites concerned, for the year 2011 it increased to 72 reports and for the year 2012 a total of 113 reports can be found.

The use of websites as a medium to promote transparency is observably utilized by the cities in Davao Region except for Digos. This practice affirms President Barack Obama of USA who believes that openness will strengthen democracy and promote efficiency and effectiveness in government. However, to achieve increase transparency which decreases corruption is not possible without incorporating appropriate channels for public feedback (UNDP, 2005).

As far as the availability of the documents are concerned, a total of 612 reports were inquired from 2010-2012, however only 220 reports which could be found in all the concerned city LGU websites. Referring to the outcome presented individually wherein only the cities of Mati and Tagum has more than half of the inquired documents from the year 2010-2012, accompanied with the overall outcome reflecting that in totality a percentage of $36 \%$ is obtained as the computed extent of compliance of all the cities, it can be concluded that not all the cities complied with the FDP requirement on posting the inquired reports.

Comparison of the City Websites' Contents. The city of Davao and Tagum unexpectedly got an equal rate of 3.86 which corresponds to good remarks, this simply imply that the two city websites possessed $70 \%$ to $84 \%$ of the respondents' assessments. It was followed by the city websites of Samal and Mati for having the means of 1.91 and 1.58 respectively. The average 
rates emphasize that only $40 \%$ to $54 \%$ is the outcome of the city websites in the assessments done by the respondents; this corresponds to a poor remarks. Average rates of 1.34 and 1.18 were given consecutively to the cities of Panabo and Digos. This signifies that the city websites possessed less than $40 \%$ of the expected outcome of the respondents; this corresponds to unsatisfactory remarks.

None of the government city websites in Davao Region got an excellent remark though cities of Davao and Tagum has a lot of features but these are not queried in the checklist thus were not rated by the respondents. For Affisco and Soliman (2006) and Al-adawi, Yousafzai and Pallister (2005) for the cities of Davao Region be considered as a higher level of e-government service, the websites must possessed higher number of features and dynamic features such as online executable service.

In the respective function schemes, Function 1 and 6 both obtained a means of 2.60 and 2.70 respectively which equates to average remarks. The result tells that averagely, the information which promotes citizens awareness and understandings of the cities' characteristics and linkage between government and business were made available by all the city websites of Davao Region $55 \%$ to $69 \%$ as accorded by the expected outcome of the respondents.

For the information which promotes efficiency and effectiveness in service delivery (Function 2), transparency and accountability in operations and services (Function 3) and linkage and interaction between government, citizens and other groups (Function 5); respective rates of 2.31, 2.49 and 2.15 were the computed means. This denotes that only $40 \%$ to $50 \%$ of the expected information was being displayed in all the concerned websites; it is equivalent to a rating of poor.

Lastly, the government websites in Davao Region earned an unsatisfactory rating in posting information queried in Function 4. The rating obtained tells that averagely, the city websites in Davao Region contained less than $40 \%$ of the contents which promotes awareness of policy making process and participation in decision making. Boris and Krehely (2002) and Brody, Godschalk and Burby (2003) as cited by Chadwick (2003) noted that provision of the above contents heightened citizen' participation which is vital in ensuring that the governmental decisions and policies reflect the public interest; it decreases the doubts of the citizens and their distrust to the government.

It is noteworthy also to ponder and discuss that none of the city websites in Davao Region offer the web services through .com which are often used as a commercial site. This could be linked in to what Cresswell et al. (2007) said that, once offered as commercial site, it may indicate lack of commitment by the government in offering web services to the public. Hence, the city websites of Davao Region were made accessible having a .gov domain which clearly emphasizes that the city websites were launched as e-government sites.

Regarding the currency of information, it can be noted during the evaluation period that the city websites of Digos, IGaCoS, Mati and Panabo were not regularly updated. Appearance of this scenario hinders the citizens to be informed of the current updates of the citie's' activities. These cities must take note of what Kim, et al. (1999) as cited by Parajuli (2007) said that it 
is necessary to have updated information in the government websites as it shows the seriousness of the government to disseminate timely information in order to gain the trust of the users in general.

Moreover, in the stages of development of e-government services as indentified by Affisco and Soliman (2006) and Al-dawi et al. (2005), Davao can be regarded as already in Stage 4 the transforming stage since the website of Davao can be considered already a single-point portal which integrates all the e-government services offered by all the departments of the city. However considering Stage 3 which is the transacting level, it is observable that the city website does not offer completion of an entire service online, yet the city website can be identified to reach already on the last level.

The city website of Digos is still on Stage 1- the publishing level since its website presented only the information regarding the city in a static way. Since the website of Tagum is capable of providing downloadable forms and has a search function, it can be indentified on the interacting level, the Stage 2. The city websites of IGaCoS, Mati and Panabo can be considered also to be in the level of Stage 2 even though there were no search functions provided just making available of the downloadable form.

The above comparisons discuss how the items queried in the checklist were displayed in the case of its availability in the city websites of the concerned LGUs. However, it has been almost a decade since Siar (2007) accessed the city government websites last 2004 wherein the recorded and categorized contents became the basis of the formulated function scheme. In fact, during that time, the five city LGUs namely, Davao, Digos, Samal, Panabo and Tagum were evaluated in the study conducted by the latter (Mati was not included since only in the year 2007 when it was converted into a component city).

Hence, several enhancements with regards to the contents and featured resources and services were observed as acquired by the city government sites of the six (6) concerned LGUs during the conduct of assessment in the evaluation period. With that, the researcher believes that it is deemed necessary to enumerate the items found and to discuss how the city LGUs utilizes its availability in their official websites.

The following are the discussions of the contents and features found in the city websites in Davao Region which are not part of the checklist of Siar (2007):

Archival of FDP Reports. The required documents by FDP were archived by all the city websites in Davao Region except for Digos. This gives the possibility to browse relevant documents pertaining to the transparent actions promoted by the city LGU not just for the current but also in the previous years; thus this can also become a reference for any scholarly work such as research and case study.

Archival of News. This feature is available in the city websites of Davao and Tagum as all the news posted were archived in a page wherein citizen can query the specific new which once posted in the website.

Blogs. Blog is an avenue where people can freely write information and expressed opinions 
to be presented using any multimedia components. Once published, this will be made available to all the individuals who will be connected in the Internet. The city websites of Davao and Tagum provided a specific page wherein links of the blogs which contains updates and impressions of the city, promotion of the tourism industry were clustered together and made available to the reader. The output of the bloggers is an aid to promote the city government not just locally but worldwide.

Calendar of Events. The city website of Davao and Tagum included a feature wherein all the scheduled activities were hereby posted wherein once clicked, it displays the details of the event selected. This feature conveniently let the citizens to browse the list of events as if you are just scrolling on a calendar (literally) having a memo in every concerned event.

Current Prices of Products. The website of Tagum posted information regarding the current prices of the products available in the city market. Once visited the site, the manner of displaying the information is through providing an eye-catching link which when clicked redirects the user to the page where relevant information is provided. Having this information accessibly made available to the citizen can be considered as a transparent action concerning the benefits of the citizens. This lets the citizens be informed and encouraged to visit the site frequently.

Departmental Page. The city website of Davao allocated specific web pages in every department wherein services offered and downloadable forms were accessibly provided. The availability of the vital details as posted in every department of the city would bring rich information to the citizens in availing the services of the city.

Entry Form in Joining Events. A form regarding the events which can be downloaded by the interested citizens who want to participate was provided in the city website of Davao. The accessibility brought by the provision of this service adds convenience and encourage participation of the citizens.

Featured and Coming Events. The city website of Davao provided a page where contents about the latest and coming events were visibly displayed in the homepage enabling the citizens to be at always updated and be informed of the events in the city.

Online Publication. The city websites of Davao and Tagum made available of the online magazines in their websites which can be downloaded free of charge. According to West (2007), online information is a typical content of e-government website but in the Davao Region, only the cities of Davao and Tagum provided such.

Published Details of Website. The city website of Tagum provided information regarding the history of its city websites along with the date and the incurred development. For Parajuli (2007), making available the establishment date and/or profile of the website reveals the evolution of web activities, hence this becomes an aid in reviewing the historical development of government's online presence.

Site Map. The sole city which provided a site map on its official website is Tagum; this provides a bird's eye view of the entire site. According to Nielson (2000) and Newman and 
Landay (2000), site map as a directory of the content areas is vital to be included since it reveals the logical and structural order of a website thus adds convenience as the citizens make it easier to browse the contents of the site.

Site Requisites. The city websites of Davao and Tagum provided information regarding the compatibility concerns of its websites. The two website specifically define the browser (Chrome for Davao and Mozilla Firefox for Tagum) and the screen resolutions where the sites execute smoothly. Other than that, the two websites also included the additional plug-ins required by the websites which includes the Adobe Flash Player and Adobe Reader. Availability of the above details inhibit desire of the city governments to provide a convenient environment as the citizens browse for any information available in the websites in order to gain citizens' satisfaction.

Search Links and Bar. The provision of the quick links which redirect users to locate specific page and textboxes which conveniently search for the specific query could add convenience to the users as it promotes a friendly-user environment. As for Nielson (2000), search facilities can efficiently respond to the query, with that it allow fast information retrieval and reduce the navigation time of the users. Thomas and Streib (2003) expressed that users will highly recommend government sites which provided good aspect such as ease of use and usefulness. Hence, provision of these lets the user to visit more often the site and boost citizens' interaction.

Social Networking. The city websites of IGaCoS, Samal and Tagum utilize the advantages brought by the social networking sites such as Facebook and Twitter as proven in the embedded plug-ins posted in the websites. Facebook pages and Twitter accounts of the cities were used to interact with the citizens as the citizens can freely post comments and join in the discussions provided. The three city websites provided an avenue were citizens can interact with the government and other citizens freely and with ease as it is available 24/7. The trending use of social networking sites as a channel of interaction between government and citizens is noticeable also in some other countries of Middle East and South Africa; this heightened the stakeholders to participate thus becomes a tool for opinions sharing purposes (Demissie, et al., 2010).

Translator. The contents of the city website of Tagum can be conveniently translated into 10 different common languages used in the world. It adds convenience to the readers especially the foreigners as the websites caters it services not just locally but internationally. As a result, this could facilitate promotion of the city's tourism industry.

Visitor Counter. The city LGU of Davao and Tagum provided a counter which increments once the city website is visited. The number of visitors counted could make the citizens perceive how useful and popular the site is which somewhat creates a positive perception.

Widgets. These features were provided in the city websites of Davao, IGaCoS, Mati and Tagum wherein the manner of displaying the current climate and temperature of the cities were powered by the external links which were embedded in the sites. The illustrative and entertaining displays offered by these widgets are informative enough which adds positive 
impression to the viewers.

Manner of Posting the Required FDP Reports: A Comparison. In terms of accessibility of the reports, in the 5 cities of Davao Region complying to FDP, only the city of Davao does not provide a specific page and link where relevant documents can be accessed conveniently, all other websites make available of a link which redirects to the page where reports are displayed. To add with, only the city website of IGaCoS and Mati provide information of the reports uploaded along with the details of the published date, but not all the reports uploaded in the website of IGaCoS were accompanied with date published only the recent reports. In the city website of Mati, the manner of displaying the reports is confusing to the viewer since the query is not about the reports intended for the particular year or quarter but instead as to the date it was uploaded in the website.

The city website of Davao, Panabo and Tagum posted the reports according to what year or quarter the report is with no accompanied date but only the website of Tagum conveniently posted it in just one page since for the city of Davao not all the reports were posted on the same page though a search mechanism is provided and for the city website of Panabo it was plainly listed on the page no filtering feature provided.

In viewing the report, you have to download it first to see the content of the specific reports in the case of the websites of Davao, Panabo and Mati while for the city website of IGaCoS the report is also available for download and you can also view the content online and a feature where you can print directly the certain report is provided; as to the city of Tagum it can be viewed online and once you redirected to docs.google.com you can have it printed directly.

It can be observed also that the posted reports of the city website of Panabo were uploaded in www.sribd.com wherein not everyone can download it unless you undergo the sign-up process of the site. In Tagum, as observed, all the reports regarding FDP were uploaded in docs.google.com where you can opt to print the .pdf file though you can directly view it as it was displayed as it was displayed on the frame provided once you click certain report.

As to the format of the file which can be downloaded, all the city websites which made available of downloadable reports were having a pdf extension. The uniformity of the file format could ease the user's navigation experience (Demissie, et al., 2010).

About the accuracy and quality of the reports posted, it was observed that only the city websites of Davao and Tagum embed the city logo in all the reposts which can be viewed and downloaded from the site and followed the proper templates provided in posting the reports. Some reports uploaded by the city website of Panabo were not that clear since it was scanned only and some posting of documents does not follow the required frequency of posting if it is by quarter or just annual, the same case is observable to the city website of Mati wherein there were reports which the content does not match to its title, words which were misspelled and since it is archived directly, redundant reports were often encountered. The availability of the words which were spelled incorrectly, grammatically errors and some reports which were mistakenly uploaded could hinder the process of citizen participation Demissie et al. (2010). 


\section{MInstitute ${ }^{\text {Mech }}$}

Journal of Public Administration and Governance

ISSN 2161-7104

2017, Vol. 7, No. 3

The authors added that the occurrences of the mentioned erroneous actions could raise doubt among English-speaking citizens and tourist regarding the commitment of the government to offer reliable e-government services.

The city website of IGaCoS also did posting of the reports not following the guidelines of the frequency of posting, some documents were summarized reports and not done quarterly, other reports were done quarterly which should be annual. Bulky documents can be found on all the websites since most of the sites posted individual reports with regards to the bidding and some other documents as posted but the city website of Tagum organized the manner of displaying it.

Out from the discussion presented it can be concluded that all the cities in Davao Region except for Digos practice the culture of transparency via ICTs capabilities as the medium. Through this, it enhances the degree of accountability of the cities and shows the ability of the officials spearheading the city to interact with citizens through e-governance. This proves the idea of Wong and Welch (2009) that websites serve as medium in comparing various aspects and features which promotes transparency as brought by e-governance.

\section{Conclusions}

Based on the findings of the study, several conclusions were drawn as presented in the subsequent discussions.

Website Contents. In the checklist used from the study of Siar (2007) where there were six functions with corresponding number of items specifically querying for the contents of information a website promotes, minimal outcomes are accessible to all the cities in Davao Region except for Davao and Tagum. There are some available contents and advanced features in the websites of Davao Region which are not included in the checklist used. The contents of the city website of Digos were found to be mostly empty in view of the slight availability of information, dead links and inaccurate display of information; though a website is accessible technically, it is almost useless. Therefore, it can be concluded that not all the essential information queried in each of the function scheme were made available by the cities' websites in Davao Region.

Even by that, generally, the city websites are into the promotion of information which incites civic engagement and striving to make the government more accountable and transparent .It can be proved out of the obtain online information and services as offered to the citizens.

In specific terms, majority of the contents of information available in the city websites are those related to the linkage between the LGUs and the business sectors. However, lack of information relating to the citizens awareness of policy making process and participation in decision making can be observed in all the city websites of the LGUs concerned. To add with, it is notable that there is a deficiency in displaying vital information and resources which enhance the quality and speed of service delivery.

With all due fairness in the concerned sites, improvements regarding the availability of contents are noticeable especially in the city website of Panabo where Siar (2007) described it 
as an almost useless website when it was accessed last 2004.

Compliance to FDP. Since the FDP was implemented last 2010, all the city websites are compliant in posting the required reports as depicted in the increasing number of reports accessed in 3-year time. But this is exceptionally false in the city website of Digos since there is no report can be found in the site. It can be noted also that the city website of Mati as the one garnered the highest percentage in making available the documents inquired.

With that, it is fair to conclude that all the city websites in Davao Region were compliant to FDP in posting the required reports except for the city government website of Digos.

Comparison of the Contents of the City Websites. Every department of the city of Davao has its own specific page detailing the departments' own resources and services in its website where rich information was provided in each of the department. With these, some contents are not instantly visible and easily to be accessed since you need to have it located on some other page, a sort of possibility is open in the case the researcher overlooked some information which are available in the city. Meanwhile, Tagum website provided a convenient way in displaying the contents on its homepage. Contents of information were categorized orderly according to menu and varied sectors; some other links and pages were also clustered orderly. In the websites of IGaCoS, Mati and Panabo, information cited are not that rich and limited only to standard information and most of the contents are displayed through text in static mode.

Manner of Posting of the FDP Reports. Not all the contents uploaded in the city website of Davao can be visibly located. The queried reports relevant to FDP were not displayed on the same page with that there is a tendency that the researcher overlooked some reports which are available in the site. Further, no specific searching or filtering feature was provided to conveniently search specific report.

Relatively low reports can be obtained in the city websites of IGaCoS since reports inquired start in the year $2010-2012$. This is due to the fact that most of the relevant reports posted in the website of IGaCoS are recent reports for the year 2013. Panabo website displayed the reports not in organize way as it's plainly displayed all the reports in a list format and lengthy pages.

Some documents uploaded in the city website of Panabo were distorted and blurred; one of these is the Gender and Development report for the year 2012. There were also reports which were repeatedly uploaded in the city website of Mati and the Annual Procurement Plan provided is a different report which is a Notice to Conduct Direct Contracting.

Not all the reports uploaded by the city websites followed the guided template provided in posting the concerned reports. The researcher encountered difficulty in determining the availability of all the inquired reports available in the city websites since some reports uploaded are not by quarter or annual oftentimes it was updated monthly and bidding reports are posted every bidding occurs in any item. With that, reports which are not completely available as to the inquired frequency of posting or the covered month per quarter are not counted. The same action was done to the reports which are uploaded incorrectly and the 
reports which are not clear but reports are counted even though the format is not the same as the guided one.

\section{Recommendations}

On the basis of the conclusions, the following are the recommendations:

Generally, concerned government websites must display informative contents which are rich and updated not just some standard information and outdated one. Recent news must be posted on the homepage and obsolete news must be kept on archive where citizen can query according to the date happened.

Concerned LGUs must strive to make available of the recent ordinances approved and the resolutions in their websites. In this way, citizens will be aware of the recent developmental actions initiated by the government for the city and this could answer the questions which boggles the mind of the citizen thus this could avoid any misinterpretation and enhance the level of citizen's participation.

The use of social networking site which is Facebook would be an ideal feature to be embedded in the sites in getting online surveys and polls. In the extreme number of users the social networking sites has, where online people are rampant, it could be the best way to have an official Facebook page to be acquired by the city LGU where citizens can follow and be updated on any recent update posted in the government Facebook page. This will keep the citizens be updated and at the same time promotes the page to some other friends in the social site.

Regarding the discussions and chat capability of the websites, LGU must set a specific page in the website where registered citizens through email addresses can open a discussion or can chat and discuss with other registered users. On the other hand, features of the social networking sites like Facebook and Twitter can be utilized where authorized personnel can post topic subject for discussion just like what the city websites of Davao and Tagum did. Plug-ins for Facebook and Twitter must then be installed in the sites in order for the post, comments and updates will be synchronized in the websites. Having those mentioned communication tools could lower the cost of participation while enhancing citizen involvement.

Downloadable forms intended for applying any transactions catered by the LGU must be made available in the site and ready to be downloaded; it could add convenience also to provide a file uploading capability to directly send the accomplished form. Making available some forms and information which are mostly requested by the citizens would become a reason for the citizen to frequently visit the site.

Specific sites of IGaCoS, Mati and Panabo must include vital information on the departments and offices and other business sectors available in the LGU with complete contact information which could include email addresses, telephone/fax numbers and mobile numbers. Further, to promote tourism and access to any business establishment, contact of information must also be included. 


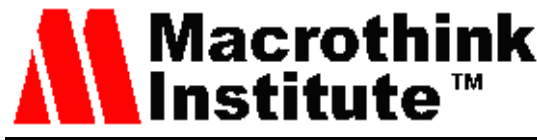

Journal of Public Administration and Governance ISSN 2161-7104 2017, Vol. 7, No. 3

To establish user-friendliness, site requirements and requisites are best to be displayed in the site accessibly in the homepage and links to obtain additional software must be provided also. Further a page intended for the frequently asked questions (FAQs) must be provided to cluster all the most asked questions thus most probably answer the possible questions queried by the citizens. The above actions add convenience to the citizens while exploring the page.

The Local government unit of Digos must develop its government site by providing the necessary contents needed to be displayed in the website, enhance the design and appearance of its web pages, and should make available of some features which requires user's interaction. Further, the city government should practice transparency by posting the governmental budgets and spending in its official website.

In displaying reports required by the FDP, even though city LGUs are required to submit the reports at the FDP portal, it is best to provide a specific page in the site where all relevant reports required are posted. With regards to the format, the template guide provided by the FDP in the FDP portal should be followed. To add convenience to the inquiring citizen in accessing the reports, reports should be named appropriately and must be clustered according to category; this should be sorted in chronological order specifying the date published. However, it is recommended to provide a search function specifically intended for querying any related report which must be made available on the same page where the reports are posted. It is best to display the transparency seal in the government site.

The focus of this study is the assessment of the contents available in the websites which leads to the comparative discussions in each of the contents available. Though the study was able to identify the lacking contents in each of the city websites concerned, it overlooked the design development, accessibility, usability and security and implementation of the websites. Hence, it is recommended by the researcher that future research be conducted, this time with on the said indicators.

\section{References}

Abangan, J. (2012, May 15). New Panabo City Wet Market Project Starts. Retrieved March 10, 2013 from Philippine Information Agency Web site: http://www.pia.gov.ph/news/index.php?article=1591337044629

Access to Budget and Expense Information of the Network of Congresses for Legislative Transparency

Al-adawi, Z., Yousafzai, S., \& Pallister, J. (2005). Conceptual model of citizen adoption of e-government. The Second International Conference on Innovations in Information Technology. Retrieved March 11, 2013, from http://www.itinnovations.ae/iit005/proceedings/articles/G_6_IIT05-Al-Adawi.pdf

Affisco, J., \& Soliman, K. (2006). e-Government: A strategic operations management frameworkfor service delivery. Business Process Management Journal, 12, 13-21. https://doi.org/10.1108/14637150610643724

Australian Government Web Guide. Retrieved March 13, 2013 at http://webguide.gov.au/ 
Best Practices in Davao Region. Retrieved January 30, 2013 from DILG Davao Region Web Site: http://www.dilgxi.org/v1/index.php/services/lgrrc/best-practices/87-services/lgrrc

Bell, C. et al. (2010). Scottish Government Website Evaluation Study 2010. Retrieved January 14, 2013 from Feather Brooksbank Web site: http://www.scotland.gov.uk/Publications/2010/09/web-evaluation-2010/Summary

Civil Society Index Summary Report (2008-2011). Bridging the Gaps: Citizens, Organizations and Dissociation. Trust, Apathy and Participation.Civil. Retrieved March 10, 2013 from www.civicus.org

Cordon, J.C. (2010). Budget Transparency Limited to Few People. Retrieved December 18,2012 from Manila Times cited by the Trade Union Congress of the Philippines Web site: http://www.tucp.org.ph/news/index.php/2010/10/budget-transparency-limited-to-few-people/

Darlington, B. and Pitts, T. (2012, September 18). Making the most out of council websites. Insight and engagement hub. Retrieved January 7, 2013 from the Local Government Network Web site: http://www.guardian.co.uk/local-government-network/2012/sep/18/council-websites-navigati on-change

Davao City Profile. Retrieved January 19, 2013 from the Official Government Website of Davao City Web site: http://www.davao.us/home.htm

Demissie, A., et. al (2010). A Comparative Study of Contents of e-Government Service Websites of Middle East and North African (MENA) Countries. C.G Reddick (ed.), Comparative e-Government, Integrated Series in Information. Retrieved March 12, 2013 from University of Tennessee Web site: http://works.bepress.com/devendra_potnis/8/

Diaz, A. (2009). e- Government in the Philippines. Retrieved March 11, 2013 from www.dti.gov.ph

Digos City Profile. Retrieved January 19, 2013 from the Official Government Website of Digos City Web site: https://sites.google.com/site/abantedigoscity/

Epal and Linden (2010). PTF Case Study Series No. 20. Organizing and Sustaining Civil Society-led Procurement in the Philippines from Partnership for Transparency Fund.

Farhan, H. and Sanderson, M. (2007). Measuring the Quality of E_Government Folksonomy. Retrieved January 18,2013 from Department of Information Studies University of Sheffield Web site: http://www.seg.rmit.edu.au/mark/.../my.../e-Government_Folksonomy.pdf

Future of e-Government: AGENDA 2020. OEDC E-Leaders Conference (2008) Retrieved January 9, 2012 from OECD e-Government Studies Web site: http://www.oecd.org/governance/eleaders/39820029.pdf

Gil-Garcia, R., \& Pardo, T. (2005). e-Government success factors: Mapping practical tools to theoretical foundations. Government Information Quarterly, 22(2), 187-216. https://doi.org/10.1016/j.giq.2005.02.001 


\section{Macrothink}

Journal of Public Administration and Governance ISSN 2161-7104 2017, Vol. 7, No. 3

Goldkuhl, G. and Rostlinger, A. (no date).Clarifying Government - Citizen Interaction: From Business Action to Generic Exchange. Paper submitted to the $4^{\text {th }}$ Scandinavian Workshop on eGovernment, Orebro

Hill, Hermann (n.d). Citizen Participation and New Perspectives in the Multimedia Era. Retrieved date March 13,2013 at www.dhv-speyer.de/hill/Publikationen/Citizen.pdf

Ilago (2001). participation, the Internet and Local Governance: A Review of Philippine Local Government Websites. Asian Review of Public Admiistration, Vol. XIII, No. 2 from National College of Public Administration and Governance, University of the Philippines

IGaCos City Profile. Retrieved January 29,2013 at Samal City Official Government Website Web site: http://samalcity.gov.ph

Irvin, R. and Stansbury, J. (2004). Citizen participation in Decision Making: Is it Worth the Effort?

Inside Cityhall- Naga City. Retrieved March 15, 2013 from www.naga.gov.ph/cityhall/city_depts.html

Kalra, S. and Verma, M. (2005). Designing Effective Websites for e-Governance. Retrieved January 23, 2013 Web site: www.cddc.vt.edu

Lallana, E. et al.(2002). e-Government in the Philippines: Benchmarking Against Global Practices. Retrieved January 17, 2013 from Digital Philippines Web site: http://www.digitalphilippines.org

Layne, K., \& Lee, J. (2001). Developing fully function e-government: A four stage model. Government Information Quarterly, 18(1), 122-136. https://doi.org/10.1016/S0740-624X(01)00066-1

List of Cities in the Philippines. Retrieved January 24, 2013 from National Statistical Coordination Board Web site: http://www.nscb.gov.ph/activestats/psgc/listcity.asp

Mati City Profile. Retrieved January 19, 2013 from the Official Government Website of Mati City Web site: http://www.mati.gov.ph/

Mindanao Times (2012, September 19). City Gets Seal of Good Housekeeping. Retrieved March 11, 2013 Web site: http://www.mindanaotimes.net/editorial-city-gets-seal-of-good-housekeeping/

Moriones (2011). Samal: Only City Awarded of Good Housekeeping. Retrieved March 11, 2013 from Philippine Information Agency Web site: http://archives.pia.gov.ph/?m=7\&r=R11\&id=54938\&y=2011\&mo=09

National Technology Readiness Survey (2001). A Summary Report. Retrieved January 19, 2013 from University of Maryland Web site: www.rhsmith.umd.edu

New Zealand Specific Requirements, Retrieved date: March 13,2013 from New Zealand Government Web Toolkit Web site: http://webtoolkit.govt.nz/standards/nzgws-2/ 
Nova Scotia, Province of Canada. Web Design and Content Standards. Retreived date: March 13, 2013 at http://novascotia.ca/cns/web-guide/

Oates, B. (2003). The Potential Contribution of ICTs to the Political Process. Electronic Journal of e-Government Volume 1 Issue 1, 2003(pp 31-39). Retrieved January 8, 2012, from http://www.ejeg.com/issue/download.html?idArticle=216

Obama (2009). Open Government Initiative. Retrieved date March 13,2013 at www.whitehouse/gov/open

Ong, C.Z (2012). Jesse's Crown Jewel: Full Disclosure Policy. Retrieved December 18,2012 from Manila Bulletin Publishing Corporation Web site: http://mb.com.ph/articles/370486/jesse-s-crown-jewel-full-disclosure-policy\#.UM_2F3fheSo

O'Donnell, O., Humphreys, P. and Timonen, V. (2003). e-Government and the Decentralisation of Service Delivery. CPMR Discussion Paper 25. Retrieved date March 13, 2013 from Institute of Public Administration Web site: www.ipa.ie

Panabo City Profile. Retrieved January 19, 2013 from the Official Government Website of Panabo City Web site: http://www.panabocity.gov.ph/

Paloma, J. (2011, November 10). Davao is World's $87^{\text {th }}$ Top City. Retrieved January 24, 2013 from Sun Star Davao Web http://www.sunstar.com.ph/davao/local-news/2011/11/10/davao-worlds-87th-top-city-189867

Parajuli, J. (2007). Content Analysis of Selected Government Web Sites: A Case Study of Nepal. Retrieved March 11, 2013 from Electronic Journal of e-Government Volume 5 Issue 1 2007(87-94) Web site: www.ejeg.com/issue/download.html?idArticle=91

Phillips, D. 2001, Online public relations, Kogan Page Limited, London.

PIA Press Release (2011, October 20). City of Tagum Lauded for Excellent Governance

Rahman, H. (2010). Framework of e-Governance at the Local Government Level. C.g Reddick (ed.), Comparative e-Government, Integrated Series in Information Systems 25, DOI 10.1007/978-1-4419-6536-3_2.Retrieved February 08, 2013 from Springer Science+Business Media, LLC $2010 \quad$ Web site: http://www.springer.com/ https://doi.org/10.1007/978-1-4419-6536-3_2

Reddick, C (2004). Citizen Interaction with e-Government: From the Streets to Servers?. Government Information Quarterly 22 (2005) 38-57. Retrieved March 13, 2013 from Department of Public Administration, The University of Texas Web site: https://docs.google.com. https://doi.org/10.1016/j.giq.2004.10.003

Siar, S. (2007). e-Governance at the Local Government Level in the Philippines: An Assessment of City Government Websites. Retrieved January 7, 2013 from Philippine Institute for Development Studies Web site: http://dirp4.pids.gov.ph/ris/pjd/pidspjd05-2egovernance.pdf

Steins, C. (2002, September). e-Government: The Top 10 Technologies. Retrieved January 24, 
2013 from Urban Insight Web site: http://www.urbaninsight.com/articles/egov0902.html

Tagum City Profile. Retrieved January 17, 2012 from the Official Website of Tagum City Web site: http://www.tagumcity.gov.ph/about_tagum.html

Thomas, J. and Streib, G (2003). The New Face of Government:Citizen-Initiated Contacts in the Era of e-Government. Journal of Public Administration Research and Theory, Vol. 13, no. 1, pp. 83-102. Retrieved March 13, 2013 at books.google.com.ph. https://doi.org/10.1093/jpart/mug010

TRANSPARENT AND ACCOUNTABLE GOVERNANCE, PHASE 3 (TAG3) PROJECT. Retrieved January 28, $2013 \quad$ at http://philippines.usaid.gov/programs/economic-growth/transparent-accountable-governance

UN Global e-Government Readiness Report (2005). Retrieved January 25, 2013 from unpan1.un.org

United Nations (2005). The Key to Increasing Transparency in e-Government Deployments, APDIP e-Note 3. Public Feedback Mechanism. Retrieved March 13, 2013 at www.apdip.net/apdipenote/3.pdf

United Nations e-Government Survey (2008). From E-Government to Connected Governance. Retrieved March 10, 2013 from http://www.unpan.org/egovkb/global_reports/08report.htm

United Nations e-Government Survey 2010. The State of e-Government around the World (Part 2). Retrieved date: March 13,2013 at https://docs.google.com/

United Nations e-Government Survey (2012): Towards a More Citizen Centric Approach. Retrieved date: March 13, 2013 from Department of Economic and Social Affairs Web site: https://docs.google.com

What's New in DILG?Full Disclosure Policy. Retrieved January 28, 2013 at http://www.dilg.gov.ph/whatsnew.php?id=39

Weiss, C. (1998) Evaluation: Methods for Studying Programs \& Policies 2nd edition. Prentice Hall

Wong, W., \& Welch, E. (2009). Does e-Government promote accountability? A comparative analysis of Website openness and government accountability. Governance, 17(2), 275-297. https://doi.org/10.1111/j.1468-0491.2004.00246.x

You and Lee (2011). Budget Transparency and Participation- Korean Case Study.

\section{Copyright Disclaimer}

Copyright for this article is retained by the author(s), with first publication rights granted to the journal.

This is an open-access article distributed under the terms and conditions of the Creative Commons Attribution license (http://creativecommons.org/licenses/by/4.0/). 